\title{
O Sistema Nacional de Pós-graduação (SNPG) e o Plano Nacional de Educação (PNE 2014-2024): regulação, avaliação e financiamento
}

\author{
The National System of Graduate Studies (SNPG) and the National Education \\ Plan (PNE 2014-2024) in brazil: regulation, evaluation and funding \\ El Sistema Nacional de Posgrado (SNPG) y el Plan Nacional de Educación (PNE \\ 2014-2024) en brasil: regulación, evaluación y financiamiento \\ MÁRIO LUIZ NEVES DE AZEVEDO \\ JOÃO FERREIRA DE OLIVEIRA \\ AFRÂNIO MENDES CATANI
}

Resumo: Este artigo problematiza a relação entre o Sistema Nacional de PósGraduação (SNPG), o Plano Nacional de Educação (PNE 2014-2024), o Plano Nacional de Pós-Graduação (2011-2020) e a política de formação de pessoal de educação superior (graduação e pós-graduação), considerando as imbricações entre financiamento, regulação e avaliação. $O$ artigo também trata sobre a formação superior para o magistério na educação básica, bem como sobre potenciais impactos do corte de financiamento da CAPES (2015-2016) por intermédio do Programa de Apoio à Pós-Graduação (PROAP) e do Programa de Excelência Acadêmica (PROEX).

Palavras-chave: Pós-graduação; PNE 2014-2024; financiamento; CAPES; educação superior.

\begin{abstract}
This article problematizes the relationship between the National System of Graduate Studies (SNPG), the National Education Plan (PNE 2014-2024), the National Plan for Graduate Studies (2011-2020) and the Training policy for higher education staff (undergraduate and graduate) in Brazil, considering the overlapping of funding, regulation and evaluation. The article also deals with the higher education for teaching in basic education, as well as the impacts of cut in funding of CAPES (2015-2016) through the Support Program for Graduate courses (PROAP) and the Academic Excellence Program (PROEX).
\end{abstract}

Keywords: Graduate course; PNE 2014-2024; funding; CAPES; higher education.

Resumen: Este artículo problematiza la relación entre el Sistema Nacional de Posgrado (SNPG), el Plan Nacional de Educación (PNE 2014-2024), el Plan Nacional de Posgrado (2011-2020) y la política de formación del personal de educación superior (grado y posgrado), considerando las imbricaciones entre financiamiento, regulación y evaluación. El artículo también trata de la formación superior para la enseñanza en la educación básica, así como de potenciales 
impactos de recortes de financiación de la CAPES (2015-2016) a través del Programa de Apoyo al Posgrado (PROAP) y del Programa de Excelencia Académica (PROEX)

Palabras clave: Posgrado; PNE 2014-2024; financiamiento; CAPES; educación superior.

\section{INTRODUÇÃO}

\footnotetext{
Todo campo, como o campo científico [...] é um campo de forças e um campo de lutas para conservar ou transformar este mesmo campo de forças. (BOURDIEU, 2004, p. 22-23).
}

O campo acadêmico ou o científico, como todo campo social, é caracterizado por disputas, alianças e relações (BOURDIEU, 2004).O reconhecimento pelos pares, a autoridade científica e a distinção acadêmica são os objetos simbólicos de disputa nesse campo específico. Ao agirem, os atores sociais respondem ao desafio de conquistar maior autonomia do campo acadêmico em relação a outros espaços sociais, em especial ao campo do poder - ou o Estado propriamente dito.

Essa tarefas e torna ainda mais complexa nos dias atuais, pois se vive, ao mesmo tempo, 1) a chamada "quarta revolução tecnológica", que seria o momento da "smart factory" (da indústria inteligente), caracterizada pela automação, pelos sistemas cibernéticos, pela Internet das coisas e pela computação em nuvens (SCHWAB, 2016); 2) a economia baseada no (cercamento do) conhecimento (AZEVEDO, 2013); 3) o avanço da internacionalização e da transnacionalização da Educação Superior e da ciência (AZEVEDO, 2015;AZEVEDO; CATANI, 2013).

Os atores que interagem no campo acadêmico nacional, frente a tais desafios, procuram estabelecer alianças internacionais (internacionalização) e estimular o campo do poder - por intermédio das agências de fomento e, às vezes, em parceria com entes privados - a financiar projetos e programas de pesquisa para fazer frente à luta pelo avanço do conhecimentoe da ciência no País, mesmo que, para isso, como veremos adiante, sejam sacrificadas determinadas áreas de conhecimento, a exemplo das Humanidades (negativa e preconceituosamente chamadas de soft science), que não gozam do devido reconhecimento dos atores sociais nas interseções dos campos (poder e academia), desviando o complexo fluxo de financiamento para as ciências naturais (bard science - como se fosse superior àsoft, o outro lado do preconceito).

Diante do complexo panorama de competição global pelo conhecimento (e pelos fundos de financiamento), nosso artigo problematiza a relação entre 
oSistema Nacional de Pós-Graduação (SNPG), o Plano Nacional de Educação (PNE 2014-2024), o Plano Nacional de Pós-Graduação 2011-2020 e a política de formação de pessoal de Educação Superior (graduação e pós-graduação), discutindo, em especial,o magistério na Educação Básica, considerando as imbricações entre financiamento, regulação e avaliação. Especial atenção é dada, ainda, à formação para o magistério na Educação Básica, bem como aos impactos da nova matriz de custeio do Programa de Apoio à Pós-Graduação (PROAP) e do Programa de Excelência Acadêmica (PROEX) da Coordenação de Aperfeiçoamento de Pessoal de Nível Superior (CAPES).

\title{
A QUARTA REVOLUÇÃO INDUSTRIAL E A ECONOMIA BASEADA NO (CERCAMENTO DO) CONHECIMENTO
}

\begin{abstract}
Estamos à beira de uma revolução tecnológica que irá alterar fundamentalmente a maneira como vivemos, trabalhamos e nos relacionamos com os outros. Em sua escala, escopo e complexidade, a transformação será diferente de tudo o que a humanidade havia experimentado antes. Ainda não sabemos exatamente como isso vai se desenrolar, mas uma coisa é clara: a resposta a ela deve ser integrada e abrangente, envolvendo todas as partes interessadas (stakeholders) da política global, dos setores públicos e privados à academia eà sociedade civil' ${ }^{1}$.(SCHWAB, 2016 tradução nossa).
\end{abstract}

O autor da preditiva epígrafe, o economista e engenheiro alemão Klaus Schwab,que afirma que o mundo está próximo de entrar na quarta revolução industrial, foi o fundador do Fórum de Gestão Europeia, que se tornou, em 1987, o Fórum Econômico Mundial. Apesar de possuir sede na cidade de Coligny (Genebra-Suíça),ele é mais conhecido pelo local da reunião anual que acontece em Davos, na Suíça. Assim considerando, as três revoluções antecedentes possuem, esquematicamente, características marcantes. A primeira revolução industrial usou a água e o vapor como força mecânica. A segunda utilizou a energia elétrica para criar a produção em massa. A terceira aplicou a eletrônica e a tecnologia da informação para automatizar a produção. Agora, para Schwab, a quarta revolução industrial está construindo-se sobre a terceira; é uma revolução digital que vem ocorrendo desde meados do século passado, caracterizada pela fusão de tecnologias que estão fundindo fronteiras entre o físico, o digital e o biológico. (SCHWAB, 2016).

$1 \quad$ No original: "We stand on the brink of a technological revolution that will fundamentally alter the way we live, work, and relate to one another. In its scale, scope, and complexity, the transformation will be unlike anything humankind has experienced before. We do not yet know just how it will unfold, but one thing is clear: the response to it must be integrated and comprehensive, involving all stakeholders of the global polity, from the public and private sectors to academia and civil society". 
Entretanto, em escala global, a quarta revolução industrial está ocorrendo sob os mandamentos do capitalismo. Isto é, a indústria 4.0, referenciada na economia baseada no conhecimento,conforma um conjunto de inovações e invenções para a produção de mercadorias, como diria Marx, não importando seus destinos, se essas mercadorias servirão para a satisfação de necessidades físicas, espirituais ou no domínio da fantasia:os ganhos tendem a ser recuperados e concentrados nos centros do poder político e econômico ${ }^{2}$. Sob o capital, a Quarta Revolução Industrial é, em essência, a conformação da economia baseada no (cercamento do) conhecimento ${ }^{3}$. Segundo Azevedo (2013),

A economia baseada no conhecimento não é exatamente uma mudança de paradigma em que se saltaria para uma economia baseado em serviços e na produção de bens de alto valor agregado; tem sido, na realidade, uma ideologia de inculcação do habitus individualista, da responsabilização do trabalhador por sua empregabilidade, da mercadorização da oferta da educação e do "cercamento" do conhecimento. A partir desse ponto de vista, pode-se dizer que a economia baseada no conhecimento em nada muda a situação de submissão da força de trabalho ao controle capitalista, tampouco modifica a essência da luta de classes; ao contrário,no final das contas, torna-se um dos fatores de contradição entre as forças produtivas e as relações de produção, que pode colocar em xeque, em certo momento, a distribuição de poder e de renda na sociedade e o próprio sistema de produção baseado em mercadorias. (p. 109-110).

A partir da concepção de que o mundo da produção se encontra ingressando na quarta revolução,o campo do poder (o Estado) e as agências de fomento à pesquisa e à pós-graduação formulam políticas e publicam editais que priorizam as chamadas ciências naturais, criadoras de tecnologias, invenções e inovações materiais, em desapreço às Humanidades, com o propósito de obter vantagens competitivas no mundo da produção de mercadorias. Todavia, as Humanidades são imprescindíveis no processo de desenvolvimento geral. Afinal,

2

"A riqueza das sociedades em que domina o modo de produção capitalista aparece como uma 'imensa coleção de mercadorias' [...]. A mercadoria é, antes de tudo, um objeto externo, uma coisa, a qual pelas suas propriedades satisfaz necessidades humanas de qualquer espécie. A natureza dessas necessidades, se elas se originam no estômago ou da fantasia, não altera nada na coisa”. (MARX, 1983, p. 45).

3 "A expropriação de saberes, da cultura e da ciência e a mercadorização da educação, do conhecimento e da criação científica, podem ser compreendidas como uma espécie de privatização e de 'cercamento' de bens públicos intangíveis. A exemplo dos enclosures das terras comuns na Inglaterra a partir do século XVI, como bem retrataram Thomas Morus n'A Utopia e Marx no capítulo de O Capital dedicado 'A Assim Chamada Acumulação Primitiva', está havendo 'cercamentos' de bens comuns que, até recentemente, costumavam ser compartilhados. Assim, conhecimentos, saberes, ciência e cultura [...] vêm sendo 'cercados' [...]. O Acordo Relativo aos Aspectos do Direito da Propriedade Intelectual Relacionados com o Comércio (Agreement on Trade-Related Aspects of Intellectual Property Rights), proveniente de negociações no âmbito da Rodada Uruguai no Acordo Geral de Tarifas e Troca (GATT), em 1944, sob a guarda da OMC [Organização Mundial do Comércio], tem o sentido de legalizar nacionalmente as regras acordadas em reuniões do GATT e da OMC relativas ao 'cercamento' do conhecimento e da criação humana”. (AZEVEDO, 2013, p. 100-101). 
pergunta-se: ciência para quem? Qual é a ética na produção cientifica? Qual é o ethos de sociedade? Qual sociedade: dominada pelo mercado e pelo privado ou permeada por valores solidários e promotora do bem comum? Não se pode relegar a segundo plano a capacidade crítica e a massa crítica das Humanidades. Aliás, pensar o conhecimento é pensar no descortinamento do conhecimento e em seu desenclausuramento, sob o risco de se estar construindo uma (economia) sociedade baseada no "cercamento" do conhecimento (AZEVEDO, 2013).Em função disso, discute-se, a seguir, o Sistema Nacional de Pós-Graduação (SNPG), o Plano Nacional de Pós-Graduação 2011-2020 e o Plano Nacional de Educação (PNE) 2014-2024. Afinal, em escala nacional, que Brasil quer se construir?

\section{A PÓS-GRADUAÇÃO NO BRASIL: REGULAÇÃO, AVALIAÇÃO E FINANCIAMENTO}

\footnotetext{
É preciso escapar à alternativa da 'ciência pura', totalmente livre de qualquer necessidade social, e da 'ciência escrava', sujeita a todas as demandas políticoeconômicas. (BOURDIEU, 2004, p. 21).
}

Para além da formação de mestres e doutores no Brasil, o Sistema Nacional de Pós-Graduação (SNPG), integrado por cursos e programas de pósgraduação avaliados e reconhecidos pela Coordenação de Aperfeiçoamento de Pessoal de Nível Superior (CAPES), tem sido responsável,em grande medida, pela produção do conhecimento científico (OLIVEIRA, 2015).

Para se ter uma dimensão da evolução histórica dos cursos de pósgraduação no Brasil, vale lembrar que, em 1965, havia 27 mestrados e 11 doutorados; em 1975, 429 mestrados e 149 doutorados. Já em 2014, segundo dados do GEOCAPES, sistematizados pela Diretoria de Avaliação da CAPES e apresentados pelo professor Arlindo Philippi Jr. em conferência de abertura do XXXI ENPROP (Encontro Nacional de Pró-Reitores de Pesquisa e PósGraduação), em 2015, o SNPG estava constituído por 5.537 cursos de pósgraduação, dos quais, 1.905 doutorados, 3.105 mestrados e 527 mestrados profissionais. O gráfico a seguir demonstra a trajetória do SNPG de 1998 a 2014. 


\section{Gráfico 1 - Evolução do SNPG}

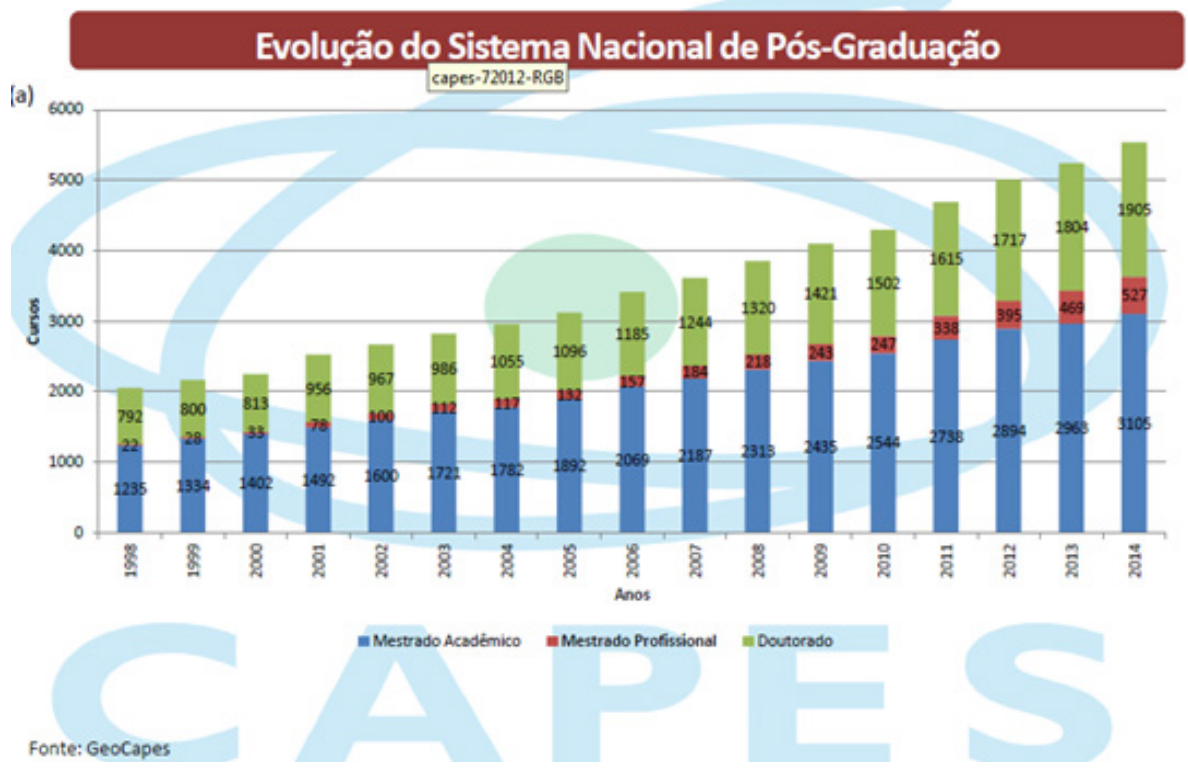

Em 2014, esses programas e cursos credenciados pela agência, mantinham,conforme dados do GEOCAPES, 302.034 pós-graduandos matriculados $^{4}$, sendo 112.363 doutorandos, 161.154 mestrandos acadêmicos e 28.517 mestrandos profissionais. Um ano após, em plena situação de crise, em que houve corte não previsto de 75\% de recursos do PROAP (Programa de Apoio à Pós-graduação) da CAPES, os doutorandos eram 120.990, os pós-graduandos de mestrado acadêmico alcançaram 167.968 e os de mestrado profissional somavam 36.272, totalizando 325.230 pós-graduandos, o que significa 7,68\% de crescimento em apenas um ano (2014/2015).(CAPES, 2016).

Agências de Fomento como CAPES, Conselho Nacional de Desenvolvimento Científico e Tecnológico (CNPq), Financiadora de Estudos e Projetos (FINEP) e as Fundações Estaduais de Apoio à Pesquisa (FAPs), são atores fundamentais no crescimento da oferta de matrículas na pós-graduação e no aumento da participação brasileira na produção científica. A Scimago Journal \& Country Rank (SJR), instituição de classificação científica, classifica mundialmente o Brasil na $15^{\mathrm{a}}$. posição em produção de artigos cientifícos. A SJR encontrou 669.280 artigos publicados por acadêmicos brasileiros entre 1996 e 2015, em periódicos por ela reconhecidos (SJR, 31 ago 2016).Para essa organização, os

\footnotetext{
$4 \quad$ Os 302.034 pós-graduandosestavam distribuídos, em 2014, segundo a unidade administrativa, entre IES Federais $(57 \%=172.179$ estudantes), IES Estaduais $(79.999=26,5 \%)$, IES privadas $(48.468=16 \%)$ e IES Municipais $(1.388=0,5 \%)($ CAPES, 2016).
} 
três primeiros países são: os EUA (9.360.233 publicações), a China (4.076.414) e o Reino Unido (2.624.530). O diretor de avaliação da CAPES apresenta tabela contendo a produção científica brasileira, de 2010 a 2014, em uma relação de 20 países (PHILIPPI JR., 2015):

\begin{tabular}{|c|c|c|c|c|}
\hline \multicolumn{5}{|c|}{$\begin{array}{c}\text { Produçāo Cientifica } \\
2010 \text { a } 2014\end{array}$} \\
\hline $\begin{array}{l}\text { capes-72012-RGB } \\
\text { RankIng por } \\
\text { produçăo }\end{array}$ & PAís & $\begin{array}{l}\text { Web of Science } \\
\text { Documents }\end{array}$ & Times Cited & $\begin{array}{c}\text { Cites per Document } \\
\text { (Impact) }\end{array}$ \\
\hline 1 & USA & 1.878 .643 & 14.645 .451 & 7,80 \\
\hline 2 & CHINA & 966.030 & 4.639 .029 & 4.80 \\
\hline 3 & ALEMANHA & 495.832 & 3.831 .060 & 7.73 \\
\hline 4 & INGLATERRA & 455.025 & 3.652 .919 & 8,03 \\
\hline 5 & JAPÃO & 388.844 & 2.199 .453 & 5.66 \\
\hline 6 & FRANÇA & 347.472 & 2.536 .424 & 7,30 \\
\hline 7 & CANADÁ & 308.219 & 2.251 .534 & 7,30 \\
\hline 8 & ITÁLIA & 294.939 & 2.069 .274 & 7,02 \\
\hline 9 & ESPANHA & 265.039 & 1.732 .078 & 6.54 \\
\hline 10 & ÍNDIA & 250.427 & 995.876 & 3,98 \\
\hline 11 & AUSTRÁLIA & 248.251 & 1.708 .110 & 6,88 \\
\hline 12 & COREA DO SUL & 243.989 & 1.186 .986 & 4,86 \\
\hline 13 & BRASIL & 187.936 & 678.619 & 3,61 \\
\hline 14 & HOLANDA & 179.721 & 1.626 .769 & 9,05 \\
\hline 15 & RÚSSIA & 145.504 & 454.599 & 3,12 \\
\hline 16 & TAIWAN & 135.558 & 652.595 & 4,81 \\
\hline 17 & SUIÇA & 130.691 & 1.279 .879 & 9,79 \\
\hline 18 & TURQUIA & 126.236 & 390.887 & 3,10 \\
\hline 19 & SUECCIA & 116.155 & 935.391 & 8,05 \\
\hline 20 & POLÔNIA & 113.011 & 472.757 & 4,18 \\
\hline
\end{tabular}

Apesar do avanço do Brasil na produção científica mundial, a massa crítica acadêmica encontra-se nos países centrais, não por acaso os mesmos espaços de concentração de poder, tecnologia e riqueza. A Worldmapper, sítio na internet organizado por David Dorling, é fonte de 696 mapas que mostram a desigualdade global em variados temas. Um desses mapas, servindo de referência para pesquisa de Laura Czerniewicz, ilustra a distribuição da produção científica mundial, demonstrando um bizarro desenho do que seria o mapa mundial de acordo com a representação do peso/volume de sua produção científica.Para Czerniewicz (2016),"criação de conhecimento e difusão são, é claro, crucialmente moldadas pelos aspectos práticos de dinheiro e tecnologia" ${ }^{5}$. Ou, ainda, parafraseando Bourdieu, a produção científica, própria do campo acadêmico, é também lugar, como outros espaços sociais, de nacionalismos e imperialismos (BOURDIEU,

5 No original: "Knowledge creation and dissemination are, of course, crucially shaped by the practicalities of money and technology". 
2002). Afinal, o conhecimento, mesmo produzido em cooperação internacional, está impregnado dos contextos dos polos conveniados (AZEVEDO; CATANI, 2013).

\section{Ilustração 1 - O Mundo da Ciência}

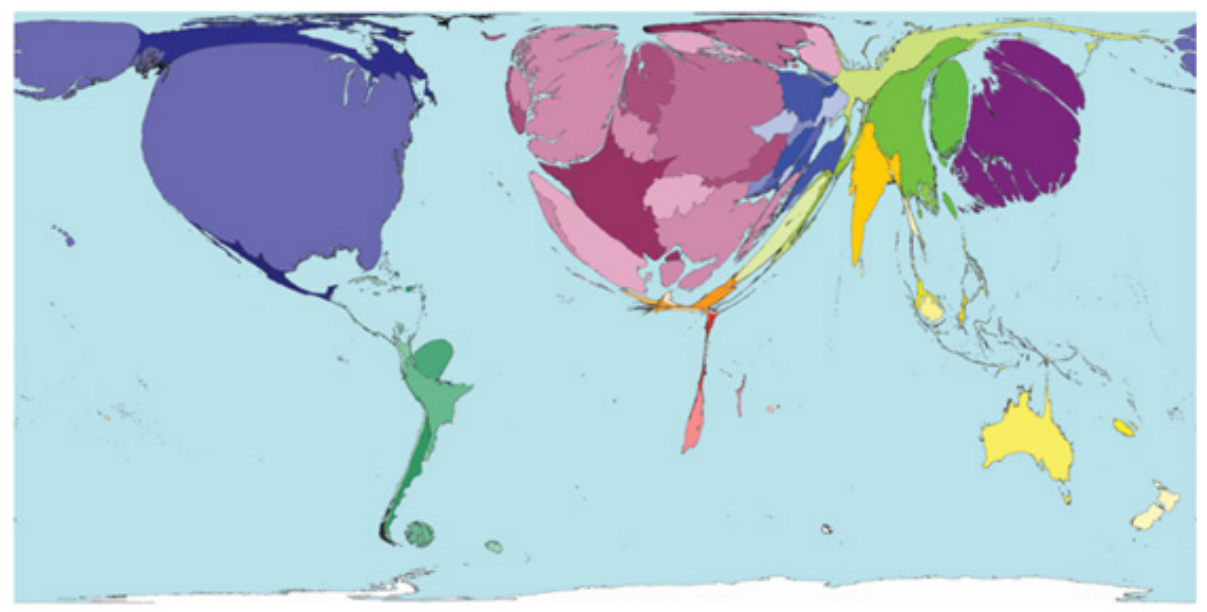

Fonte: Worldmapper.org

Nesse sentido, as agências de fomento brasileiras, tais como CNPq, CAPES, FINEP e FAPs (FAPESP, FAPERJ,FAPEMIG, FUNDAÇÃO ARAUCÁRIA-PR etc.), em grande medida, ao construírem seus editais de fomento, em lugar de valorizarem a relevância científica e a pertinência local, regional ou nacional da pesquisa, reverberam os contextos e os problemas de pesquisa dos centros do poder. São utilizados como critérios de avaliação da capacidade do proponente e de sua equipe de pesquisa a produção intelectual (re) conhecida pelos valores sociais dominantes do Norte Global, em que, cobrando por acessos e reservando copyright, fazem circular resultados de pesquisa em periódicos publicados em inglês por casas editoriais do centro do capitalismo (Elsevier, Routledge/Taylor \& Francis Group, Pearson PLC ...). Algumas dessas empresas de edição reestruturam-se, transformando-se em empresas de ensino e aprendizagem, como é o caso da Pearson, que vem "construindo problemas de política educacionais que vão gerar um mercado para seus produtos e serviços sob a forma de soluções" (JUNEMANN; BALL, 2015, p. 7 - tradução nossa). Assim, o campo educacional brasileiro, da Educação Básica à Educação Superior,

$6 \quad$ No original: "Constructing the education policy problems that will then generate a market for its products and services in the form of the solutions". 
é espaço de influência de atores de outros campos sociais, como o campo do poder e o campo das finanças. No que se refere ao espaço acadêmico,

O campo científico tem sua autonomia minorada, como é sabido, ao submeter-se à indução dos Estados e aos editais das agências de financiamento nacionais, a exemplo, com relação ao campo científico no Brasil, do Ministério da Ciência e Tecnologia (MCT), Ministério da Educação (MEC), CNPq, Capes, Finep e outras fundações de apoio à pesquisa, vinculadas aos estados subnacionais, assim como às agências internacionais, como a Fundação Ford, Fulbright, DAAD, CampusFrance, Comissão Europeia etc. (AZEVEDO; CATANI, 2013, p. 275).

Dessas agências, vale destacar, em escala nacional, a atuação da CAPES,que, fundada em 1951, desempenha papel fundamental no apoio, mas, em contrapartida, na heteronomia do campo científico, aí incluída a pós-graduação (mestrados e doutorados),pois, ao mesmo tempo, a CAPES acredita, credencia, avalia, supervisiona, financia e regula o Sistema Nacional de Pós-graduação no Brasil, estabelecendo políticas, programas e ações de manutenção e expansão.A CAPES incentiva a cooperação internacional e a internacionalização da ciência e do campo da Educação Superior. Conforme o PNPG 2011-2020,

A Diretoria de Relações Internacionais (DRI) da CAPES, foi instituída no final de 2007, sendo responsável pelos programas de bolsas no exterior (CGBE) e cooperação internacional (CGCI). Foram incrementadas associações com diversas agências congêneres de outros países, visando à concessão de bolsas em parceria e de maneira induzida, em torno não apenas de solicitações individuais, como também a partir de demandas de grupos de pesquisa e instituições de ensino superior e ainda de demandas governamentais, estas em especial através da interação com o Ministério das Relações Exteriores (BRASIL, 2010, p. 234).

O CNPq, também criado em 1951, fomenta a ciência, a tecnologia e a inovação, executando parte considerável da agenda de pesquisa do "MCTI", inclusive por intermédio da manutenção de Institutos de Pesquisas e do incentivo aos pesquisadores (Ex.: bolsa-produtividade, editais de pesquisa, bolsas especiais etc.). A cooperação internacional e a internacionalização da ciência e da Educação Superior do País recebem incentivo do CNPq. O PNPG 2011-2020 registra:

A ASCIN (Assessoria de Cooperação Internacional) disponibiliza diferentes mecanismos de financiamento à cooperação internacional para apoiar projetos de pesquisas conjuntas de alta qualidade, mobilidade de pesquisadores e treinamento de pesquisadores e formação de recursos humanos, objetivando a promoção do desenvolvimento científico e tecnológico brasileiro, em consonância com as orientações da Política Nacional de Desenvolvimento Científico e Tecnológico. (BRASIL, 2010, p. 239). 
A FINEP, segundo seus estatutos, é uma empresa pública brasileira criada em 1967 com a finalidade de "apoiar estudos, projetos e programas de interesse para o desenvolvimento econômico, social, científico e tecnológico do País, tendo em vista as metas e prioridades setoriais estabelecidas nos planos do Governo Federal" (FINEP, 1996, art. $3^{\circ}$ ). De acordo com o PNPG 2011-2020, a FINEP

Está alinhada com as prioridades da política externa brasileira, priorizando a diversificação de parcerias, com o estabelecimento de programas e projetos cooperativos em todos os continentes. $\mathrm{O}$ foco principal recai na promoção de ações de cooperação com os países da América Latina, países Africanos, China e Índia. Já com a Europa, os Estados Unidos e outros países 'centrais', priorizam-se ações de cooperação em temas de interesse nacional, com base no princípio da reciprocidade. (BRASIL, 2010, p. 241).

Em escala subnacional, as FAPs, vinculadas a 26 Estados e ao Distrito Federal (somente o Estado de Roraima não tem FAP), alocam apoios à pesquisa e à pós-graduação. O PNPG 2011-2020 reconhece que "para buscar maior sucesso na política de pós-graduação, as ações a serem adotadas em âmbito nacional não podem prescindir da participação das Fundações de Amparo à Pesquisa" (Idem, p. 268). Ademais, com relação à internacionalização, o CONFAP (Conselho Nacional das Fundações Estaduais de Amparo à Pesquisa) "estabeleceu seu primeiro acordo internacional em 2011, com a França (Centre National de la Recherche Scientifique - CNRS), renovado em 2015" (CONFAP, 2016, p. 10). Possui parcerias com o Reino Unido (Fundo Newton) e Estados Unidos (Fundação Bill \& Melinda Gates) e tem enviado missões para estabelecer convênios com a Rússia, Finlândia, Bélgica e Irlanda (Idem).

Não é demais ressaltar, com ênfase, a atuação da CAPES como a agência de fomento mais influente no campo científico e no campo da Educação Superior no Brasil, uma vez que desenvolve atividades de acreditação, credenciamento, avaliação, supervisão, regulação e financiamento dos Programas de PósGraduação, que formam o Sistema Nacional de Pós-Graduação no Brasil, sendo O PROAP um de seus instrumentos de fomento?

\footnotetext{
7 A Portaria n ${ }^{\circ} 156$, de 28 de novembro de 2014, aprova o regulamento do Programa de Apoio à PósGraduação (PROAP), definido pelo "Art. 1: O Programa de Apoio à Pós-Graduação (PROAP) destina-se a proporcionar melhores condições para a formação de recursos humanos e para a produção e o aprofundamento do conhecimento nos cursos de pós-graduação stricto sensu mantidos por instituições públicas”.
} 
Dessa maneira, o corte de recursos ${ }^{8}$ ocorrido em 2015, próximo de $75 \%$ (válido somente para aquele ano), e a mudança da matriz de financiamento de custeio por intermédio do PROAP e do PROEX (válida para o ano de 2016), baseada na mediana dos programas de todas as áreas no País, traz potenciais impactos negativos para o SNPG e para o cumprimentos das metas do PNE 20142024. A "nova" matriz de custeio, de curta vigência, pois foi publicada em maio de 2016 e reformatada em setembro de 2016 com uma metodologia mais justa (conforme se perceberá mais à frente),apresentava quatro diferenciações entre os cursos de pós-graduação: 1) Diferenciação do tamanho do corpo discente: passa aplicar a mediana; 2) Diferenciação de níveis: limitado pela mediana, o valor per capita repassado ao doutorado é o dobro do mestrado; 3 ) Diferenciação de áreas de conhecimento: G1 = todas (menos as Humanidades); G2 = Humanidades; 4) Diferenciação do valor de custeio em função da avaliação do curso pela CAPES ${ }^{9}$.

Após muita luta no campo acadêmico contrariamente a essa metodologia, que foi motivo de Audiência Púbica na Comissão de Educação da Câmara dos

8 O orçamento da CAPES sofreu cortes no ano de 2015, conforme por ela anunciado em 11 de Julho de 2015. Para o PROAP e PROEX, significou uma redução de 75\%. O Fórum de Pró-Reitores de Pesquisa e Pós-Graduação (FOPROP) manifestou-se, por intermédio do Ofício 011/FOPROP/2015, de 28 de julho de 2015, endereçado ao Professor Carlos Nobre, Presidente da CAPES, com cópia para o Professor Arlindo Phillipi Junior, Diretor de Avaliação da CAPES, asseverando que "o corte de 75\% do PROAP em julho de 2015 foi um duro golpe para os Programas de Pós-Graduação, para as Pró-Reitorias de Pós-Graduação e Pesquisa e para as Universidades como um todo. Cabe destacar que várias IES já tinham empenhado mais do que os $25 \%$ a serem repassados, tendo, inclusive, muitas pró-reitorias utilizado parte da sua própria cota do PROAP para apoiar os programas 6 e 7 no primeiro semestre de 2015. Somam-se ainda, nesse contexto de crise, as dificuldades financeiras das Universidades, em todos os segmentos, causadas pela situação econômica geral do país e por cortes orçamentários que impedem que estas apoiem financeiramente seus Programas de PósGraduação". Além disso, em Ofício 009/FOPROP/2015, de 14 de julho de 2015, dirigida ao Professor Renato Janine Ribeiro, Ministro da Educação, "O FOPROP se manifesta contrário aos cortes no orçamento da CAPES, que impactam diretamente o financiamento da pós-graduação brasileira. O MEC, em comunicado do último dia 11, informou que garantirá $90 \%$ do orçamento da CAPES previsto para 2015. Ressaltamos, no entanto, que os cortes representam uma redução da ordem de $75 \%$ dos recursos de custeio (PROAP, PROEX, entre outros programas estratégicos) e de $100 \%$ de capital, destinados à manutenção dos programas de pós-graduação stricto sensu".

9 Argumentos sobre a nova matriz de custeio do PROAP e PROEX foram apresentados por um dos autores em Audiência Pública na Comissão de Educação da Câmara Federal para discutir as condições de financiamento dos programas de Pós-Graduação em Educação no âmbito da política para distribuição de recursos de custeio dos Programas de Pós-Graduação elaborada pela CAPES, conforme Requerimento $n^{\circ}$ 210/2016 da Deputada Federal Professora Dorinha Seabra Rezende a pedido da Associação Nacional de Pesquisa e Pós-Graduação em Educação (ANPED) (AZEVEDO, 2016). Agradecemos ao Professor João Batista Carvalho Nunes, da Universidade Estadual do Ceará (UECE), pelo diálogo e pelas inspirações. O Professor Nunes elaborou pertinente análise sobre os novos critérios de concessão do PROAP e do PROEX, cujo texto consta das Referências ao final do presente artigo. Anotamos também Links para acesso virtual às notícias sobre a referida Audiência Pública: 1) Portal da Câmara dos Deputados: < http://www2.camara.leg. $\mathrm{br} /$ atividade-legislativa/comissoes/comissoes-permanentes/ce/videoArquivo?codSessao $=57689 \& \operatorname{codReuni}$ $\mathrm{ao}=44671>$; 2) Portal da ANPEd < http://www.anped.org.br/news/audiencia-na-camara-com-presenca-daanped-demonstra-equivocos-de-metodologia-da-capes-no>; 3) Portal da SBPC: <http://www.jornaldaciencia. org.br/edicoes/?url=http://jcnoticias.jornaldaciencia.org.br/1-anped-reage-a-mudancas-da-capes-noscriterios-de-repasse-de-recursos-para-pos-graduacao/>. 
Deputados, em 30 de agosto de 2016 (AZEVEDO, 2016), a primeira diferenciação (mediana dos programas) foi suspensa pela CAPES no fim da primeira quinzena de setembro ${ }^{10}$. Nesse sentido, conforme aditivo ao Ofício Circular - Concessão do PROAP 2016, a mediana deixou de ser aplicada na metodologia para definição dos valores do PROAP a serem concedidos pela CAPES na última parcela de 2016,mantendo-se, no mesmo aditivo ao ofício circular, as demais diferenciações (por níveis: mestrado e doutorado;por áreas de conhecimento: G1 e G2 e por notas de avaliação) (CAPES, 2016) ${ }^{11}$. Entretanto, vale deter-se na análise acerca da metodologia de distribuição de recursos, mesmo que revogada, em razão de ter sido aplicada para distribuição de recursos do PROAP e PROEX pela CAPES até a publicação do referido aditivo ao ofício circular (setembro de 2016) e, também, para compreensão dos campos de forças (lutas) de que é exemplo o campo acadêmico, conforme chama a atenção a epígrafe deste artigo: "todo campo, como o campo científico [...] é um campo de forças e um campo de lutas para conservar ou transformar este mesmo campo de forças". (BOURDIEU, 2004, p. 22-23).

Neste sentido, conforme o anexo do Oficio Circular que define a Concessão dos valores do PROAP e PROEX/PNPD 2016 (ainda sem o aditivo), a metodologia reduziu drasticamente o repasse do PROAP aos programas de pós-graduação com mais de 39 mestrandos e 41 doutorandos matriculados e do PROEX para aqueles programas que têm mais de 45 mestrandos e 75 doutorandos. O maior impacto atingiu as Humanidades (Ciências Humanas; Ciências Sociais Aplicadas; Linguística, Letras e Artes; Multidisciplinar - Ensino e Interdisciplinar em Sociais e Humanidades), que foi desclassificada como prioridade na CAPES. Isso porque os programas de pós-graduação passam a se diferenciar em G1 e G2, estando as Humanidades alocadas na condição de G2,o que significa que a formação e a pesquisa que conformam esta macro área do conhecimento, encontra-se fora das prioridades eleitas pela CAPES.

10 De acordo com o aditivo que pôs fim às medianas como critério de distribuição de recursos do PROAP (o mesmo também valerá para o PROEX), passando a vigorar o quantitativo discente matriculado nos Programas, originalmente, reza o primeiro parâmetro do aditivo de setembro de 2016: "tamanho do corpo discente - utilizou-se o número de alunos matriculados informado na Plataforma Sucupira (maio de 2016). O 'teto baseado na mediana', utilizado na metodologia anterior, foi retirado da metodologia atual" (Ofício Circular - Concessão PROAP 2016 - Aditivo de setembro de 2016).

11 Segundo o Aditivo ao Ofício Circular - Concessão do PROAP 2016, a mais recente tabela de Matriz de custeio/aluno para os PPGs apoiados pelo PROAP é a seguinte:

\begin{tabular}{|c|c|c|c|c|}
\hline \multirow{2}{*}{ Nota do PPG } & \multicolumn{2}{|c|}{ Mestrado } & \multicolumn{2}{c|}{ Doutorado } \\
\cline { 2 - 5 } & G1 & G2 & G1 & G2 \\
\hline 3 & 308,00 & 220,00 & 462,00 & 330,00 \\
\hline 4 & 385,00 & 275,00 & 577,50 & 412,50 \\
\hline 5 & 481,25 & 343,75 & 721,88 & 515,63 \\
\hline
\end{tabular}


Tabela 1 Matriz de Distribuição de Recursos PROEX e PROAP

\begin{tabular}{|c|c|c|c|c|c|}
\hline \multirow{2}{*}{ Nível } & \multirow{2}{*}{ Grupo } & \multicolumn{4}{|c|}{ Custeio/Aluno } \\
\cline { 3 - 6 } & & Notas 6 e 7/PROEX & Nota 5/PROAP & Nota 4 /PROAP & Nota 3 /PROAP \\
\hline \multirow{2}{*}{ Mestrado } & $\mathrm{G} 1$ & $\mathrm{R} \$ 550,00$ & $\mathrm{R} \$ 315,00$ & $\mathrm{R} \$ 252,00$ & $\mathrm{R} \$ 189,00$ \\
\cline { 2 - 6 } & $\mathrm{G} 2$ & $\mathrm{R} \$ 375,00$ & $\mathrm{R} \$ 215,00$ & $\mathrm{R} \$ 172,00$ & $\mathrm{R} \$ 129,00$ \\
\hline \multirow{2}{*}{ Doutorado } & $\mathrm{G} 1$ & $\mathrm{R} \$ 1.100,00$ & $\mathrm{R} \$ 630,00$ & $\mathrm{R} \$ 504,00$ & $\mathrm{R} \$ 378,00$ \\
\cline { 2 - 6 } & & $\mathrm{R} \$ 750,00$ & $\mathrm{R} \$ 429,00$ & $\mathrm{R} \$ 343,00$ & $\mathrm{R} \$ 258,00$ \\
\hline
\end{tabular}

Fonte: Anexo do Oficio Circular da CAPES sobre PROAP/PROEX-2016

Na subárea da Educação, segundo estudos de Nunes (2016),professor da Universidade Estadual do Ceará (UECE), a nova matriz de custeio do PROAP/ PROEX faz reduzir o repasse de financiamento de novea cada dezmestrados em educação, pois estão situados em coortes superiores àsmedianas de matriculados prescritas no anexo do ofício circular da CAPES. Para as Humanidades (G2), a nova matriz de custeio reduz a participação da área de Ciências Humanas de 15\% para 5\% no montante do PROAP, significando uma diminuição imediata a $1 / 3$ do que recebia em 2014 (ANPED, 2016).Segundo Nunes (2016), levando-se em consideração a subárea de Educação,

\begin{abstract}
O critério de concessão do PROAP tomando por base a mediana do quantitativo de alunos em todos os programas de pós-graduação de todas as áreas do conhecimento é muito prejudicial à área de Educação, em virtude do tamanho do corpo discente nessa área. Somente 7,2\% dos cursos de Mestrado Acadêmico e 19,4\% dos cursos de Doutorado em Educação não irão superar o valor da mediana definido para cada nível. (p. 6).
\end{abstract}

Ademais, a médio prazo, essa política de financiamento, baseada em medianas, traria impactos. O primeiro seria a redução da oferta de vagas de mestrado e doutorado, pois induzia todos os programas a aproximarem o número de matriculados à mediana nacional. Os programas com avaliação da CAPES entre 3 e 5 tenderiam a aproximar-se do limite do financiamento per capita de 39 mestrandos e 41 doutorandos. Para os programas com avaliação 6 e 7, financiados pelo PROEX, seriam 45 mestrandos e 70 doutorandos. Alguns programas aumentariam o número de matriculados e a grande maioria diminuiria de tamanho (em especial nas Humanidades).

O segundo impacto negativo, que tenderia a ocorrer em instituições que têm médios e grandes programas de pós-graduação, seria a secessão dos 
programas por linhas de pesquisa - isto é, a nova metodologia estimula (impacto não esperado) a divisão dos programas por linhas pesquisa, levando à perda de organicidade, da solidariedade e da interdisciplinaridade.

Por fim, como terceiro impacto, contrariando o PNE 2014-2014, especialmente a estratégia 4.16, que prevê a inclusão dos profissionais da educação em cursos de pós-graduação, e a Meta 14, que prescreve "elevar gradualmente o número de matrículas na pós-graduação stricto sensu, de modo a atingir a titulação anual de sessenta mil mestres e vinte e cinco mil doutores", a referida matriz de financiamento preferia ser fiel aos mandamentos de determinados atores sociais que têm dominado o espaço de interseção entre os campos político e acadêmico, que conseguiram consignar e explicitar no Plano Nacional de Pós-Graduação (PNPG) 2011-2020 componentes de hostilidade e de discriminação negativa em relação às Humanidades. Vale citar:

O sistema deverá crescer na próxima década, pois além de ser relativamente pequeno e recente, não está saturado e poderá ser convocado para novos e importantes serviços, gerando a necessidade não apenas de crescer, mas de crescer com qualidade. $\mathrm{O}$ sistema continua formando um contingente expressivo de doutores nas chamadas Humanidades, que incluem as Ciências Humanas, as Ciências Sociais Aplicadas, as Letras e as Artes (cerca de 31\% dos alunos matriculados em doutorado no ano de 2009). (BRASIL, 2010, p. 20).

Em síntese, a CAPES, com a matriz de financiamento para os programas de pós-graduação no Brasil estabelecendo uma metodologia de distribuição de verbas de custeio com base na mediana dos alunos matriculados nos programas de pós-graduação e elegendo áreas científicas (Humanidades) como não prioriotárias (G2), estaria fazendo coro à tese da perversidade, conforme denuncia Albert Hirshman em seu clássico "A Retórica da Intransigência", em que conquistas sociais, nesse caso de maior acesso à pós-graduação, seriam consideradas negativas. O bom senso diria que essa ampliação do acesso processada nas Humanidades poderia ser replicada nas demais áreas e que, para isso, teriam apoio suplementar prioritário das agências públicas. Isto é, não se pode castigar um grupo, cortando o PROAP e o PROEX por terem ampliado a oferta de um bem público necessário ao desenvolvimento integral do País (inclusive cultural) e que, por efeito, contribui para o cumprimento de uma das metas do PNE 2014-2014, justamente aquela que visa à maior democratização da pós-graduação. 


\section{CONSIDERAÇÕES FINAIS}

É contraditório que justamente no sexto PNPG, o 2011-2020, apareça, de maneira enviesada, um indicativo para a restrição da população de mestres e doutores em Humanidades. O mesmo PNPG que apresenta o necessário diálogo com a Política Nacional de Formação de Profissionais do Magistério da Educação Básica, por intermédio do Plano Nacional de Formação de Professores da Educação Básica (PARFOR), com participação significativa das Ciências Humanas, também sugere a criação de barreiras para a oferta de vagas de mestrado e doutorado na macro área de Humanidades.

Em outras palavras, a instituição da Política Nacional de Formação de Profissionais do Magistério da Educação Básica, normalizada pelo Decreto ${ }^{\circ}$ 6.755, de 29 de janeiro de 2009, e o Plano Nacional de Formação de Professores da Educação Básica (PARFOR), instituído pela Portaria no 9, de 30 de junho de 2009, a ser coordenado pela fundação Coordenação de Aperfeiçoamento de Pessoal de Nível Superior (CAPES).Esta, a partir daí, recebeu também a incumbência, entre outras funções, de administrar a formação de pessoal para a Educação Básica a partir da Lei no11.502/2007 (AZEVEDO, 2012, p. 134), incumbência quese choca com as políticas de restrição de financiamento para a Pós-Graduação, em especial para as Humanidades.

Vale notar que, de acordo com Art. $2^{\circ}$ da referida Lei (11.502/2007), “a Capes subsidiará o Ministério da Educação na formulação de políticas e no desenvolvimento de atividades de suporte à formação de profissionais de magistério para a educação básica e superior e para o desenvolvimento científico e tecnológico do País [...]" (BRASIL, 2007). Nesse mesmo sentido, o PNPG 2011-2020, enfatizando as áreas de Engenharias, Saúde e Biológicas, destina às Humanidades a missão de refletir sobre o País e o Mundo e insiste sobre a necessidade de melhoria da Educação Básica:

\footnotetext{
Além das ênfases nas Engenharias e em diferentes áreas da Saúde e das Biológicas, estas últimas em programas de erradicação de doenças e preparação de novas vacinas, o SNPG deverá incluir, entre suas principais metas, a criação e o adensamento de centros de excelência em Humanidades com a missão de pensar o Brasil e o mundo [...]. Um tema que deve ser objeto de dedicado estudo por parte do SNPG é a melhoria da qualidade da Educação Básica, notadamente do Ensino Médio[...]. A CAPES, que cuida dos cursos de pós-graduação, recebeu novas atribuições com a criação das Diretorias de Educação Básica e tem condições de comandar os esforços para consecução dessa tarefa. A interação mais definitiva com a Educação Básica é uma maneira de reforçar a aproximação do SNPG com os interesses da sociedade. (BRASIL, 2010, p. 21).
} 
A legislação que regulamenta novas atribuições para a CAPES no âmbito da Educação Básica, visando àmelhoria da qualidade, acrescidas dos sinais e recomendações do PNPG 2011-202), flagra um jogo duplo em relação às Humanidades ou uma contradição nas políticas. A mais recente metodologia de distribuição de verbas de custeio por intermédio do PROAP e do PROEX (CAPES, 2016), que limita o financiamento a medianas de matriculados em mestrado e doutorado e que relega as Humanidades a um grupo 2 de alocação orçamentária, corrói a confiança justamente na agência que estabelece o diálogo entre o campo do Poder (Estado), o campo da educação e o campo acadêmico. Um dos autores do presente artigo escreveu o seguinte, em capítulo de livro sobre o trabalho na Educação Básica:

\begin{abstract}
A nova CAPES, assim, representa o espaço de interseção entre três campos sociais, o campo educacional (educação básica), o campo acadêmico (educação superior) e o campo do poder (o campo burocrático, o Estado propriamente dito), de modo a, com sua experiência (e poder legítimo e consagrado) na educação superior e na pesquisa, exercer o papel de catalisador na formação de pessoal docente em quantidade e com o perfil requeridos pelo Estado para a educação básica, trazendo, para isso, novas balizas e medidas para o jogo, novos objetos de disputa e morfologia e estrutura renovadas para o campo educacional.(AZEVEDO, 2012, p. 135-136).
\end{abstract}

Essencialmente, sans détour, pois não se aprofundará o assunto, mas para fins de reflexão nestas Considerações Finais, este é um exemplo de transferência de normas do campo acadêmico para o campo educacional, fazendo com que a essência das "boas práticas" (competição, indicadores e eficiência) válidas para o sucesso da Educação Superior pública no Brasil (graduação, pós-graduação e pesquisa) possam ser também direcionadas para a Educação Básica. No entanto, a exemplo do mitológico Icaro, as Humanidades e áreas afins, pela metodologia de distribuição de recursos da CAPES para o PROAP e PROEX, vigente até agosto de 2016, parecem receber asas com penas coladas a cera: basta o anúncio de alguma crise fiscal (esquentamento da luta pelo fundos públicos) e seus programas de pós-graduação (das Humanidades) começam a perder sustentabilidade ${ }^{12}$.

\footnotetext{
12 Porém, conforme apresentado anteriormente, inclusive nas notas de rodapé 11 e 12, para justo registro, em setembro de 2016, a CAPES fez reparos à metodologia de custeio por intermédio do PROAP (e PROEX), estabelecendo melhores condições da manutenção dos programas de Pós-Graduação, em especial, passando a utilizar o número de alunos matriculados nos Programas de Pós-Graduação (PPG) e o 'teto baseado na mediana', utilizado na metodologia anterior, foi retirado. Ademais, foi estabelecido um piso mínimo de R\$ 5.000,00 por PPG (CAPES, 2016)
} 


\section{REFERÊNCIAS}

ANPED. Ofício $\mathbf{n}^{\mathbf{0}} \mathbf{0 3 3}$ de 08 de junho de 2016. Destinado ao Presidente da CAPES. Rio de Janeiro: ANPED, 2016. Disponível em: < http://www.anped.org. br/ >. Acesso em: 05 set 2016

AZEVEDO, Mário Luiz Neves de. A Pós-Graduação e o PNE (2014-2024): impactos dos cortes e das novas regras da CAPES. Vídeo em Audiência Pública na Comissão de Educação da Câmara dos Deputados. Disponível em: <http:// www2.camara.leg.br/atividade-legislativa/comissoes/comissoes-permanentes/ ce $/$ video Arquivo codSessao $=57689 \& \operatorname{codReuniao}=44671 \#$ video Titulo $>$. Acesso em: 05 set. 2016.

. Transnacionalização e mercadorização da educação superior: examinando alguns efeitos colaterais do capitalismo acadêmico (sem riscos) no Brasil - A expansão privado-mercantil. Revista Internacional de Educação Superior [RIESup], Campinas, SP, v.1 n.1 p. 86-102, jul./set. 2015.

A economia baseada no "cercamento" do conhecimento: globalização, educação e mercadorias fictícias. In: CHAVES, Vera Jacob; SILVA JÚNIOR, João dos Reis; CATANI, Afrânio Mendes (Orgs.). A Universidade brasileira e o PNE: instrumentalização e mercantilização educacionais. São Paulo: Xamã, 2013. p. $95-112$.

. Formação docente e o campo educacional: políticas, regulações e processos. In: OLIVEIRA, Dalila Andrade; VIEIRA, Lívia Fraga (Orgs.). Trabalho na Educação Básica: a condição docente em sete estados brasileiros. Belo Horizonte: Fino Traço, 2012. p. 131-151.

_; CATANI, Afrânio Mendes. Educação superior, internacionalização e circulação de ideias: ajustando os termos e desfazendo mitos. Inter-Ação, Goiânia, v. 38, n. 2, p. 273-291, mai./ago. 2013.

BOURDIEU, Pierre. Os usos sociais da ciência. São Paulo: UNESP, 2004.

. Les conditions sociales de la circulation internationale des idées. Actes de la recherche en sciences sociales. v. 145, p. 3-8,déc. 2002. 
BRASIL. Ministério da Educação. Coordenação de Aperfeiçoamento de Pessoal de Nível Superior Plano Nacional de Pós-Graduação - PNPG 2011-2020. Brasília, DF: CAPES, 2010, 2 v. Disponível em: <https://www.capes.gov.br/ images/stories/download/PNPG_Miolo_V2.pdf>. Acesso em: 15 ago. 2016.

BRASIL. Lei No 11.502, de 11 de Julho de 2007. Modifica as competências e a estrutura organizacional da fundação Coordenação de Aperfeiçoamento de Pessoal de Nível Superior - CAPES. Disponível em < http://www.planalto.gov. br/ccivil_03/_ato2007-2010/2007/Lei/L11502.htm>, acesso em 30 ago 2015.

CÂMARA DOS DEPUTADOS. Comissão de Educação. Audiência Pública sobre as condições de financiamento dos Programas de Pós-Graduação. Disponível em:< http://www2.camara.leg.br/atividade-legislativa/comissoes/ comissoes-permanentes / ce /videoArquivo?codSessao $=57689 \& \operatorname{codReuni}$ ao $=44671>$. Acesso em: 05 set. 2016.

CAPES. Ofício Circular no 15/2016-CDS/CGSI/DPB/CAPES. Anexo do Oficio Circular - Concessão PROAP/PNPD 2016. Brasília, 25 de maio de 2016.

CAPES. GEOCAPES - Sistema de Informações Georreferenciadas | CAPES. Disponível em:<www.capes.gov.br>. Acesso em: 15 ago. 2016.

CAPES. Portaria n ${ }^{\circ} 156$, de 28 de novembro de 2014, aprova o regulamento do Programa de Apoio à Pós-Graduação (PROAP). Publicado no Diário Oficial da União - Seção 1, No 234, quarta-feira, 3 de dezembro de 2014. ISSN 1677-7042

CZERNIEWICZ, Laura. Inequitable power dynamics of global knowledge production and exchange must be confronted head on. Blogs da LSE Disponível em: $<\quad$ blogs.lse.ac.uk/impactofsocialsciences/2013/04/29/ redrawingthemapfromaccesstoparticipation/>. Acesso em: 01 sep. 2016.

\section{CONFAP. Apresentação do Conselho Nacional das Fundações Estaduais} de Amparo à Pesquisa. Disponível em:<http://confap.org.br/news/ apresentacao/>. Acesso em: 04 set. 2016. 
ELLIOTT, Larry. Fourth Industrial Revolution brings promise and peril for humanity. The Guardian. Disponível em:<https://www.theguardian.com/ business/economicsblog/2016/

ESCOBAR, Pepe. Geopolítica: no G20, a alternativa da China. Outras Palavras. Disponível em:< http://outraspalavras.net/capa/ geopoliticanog20aalternativadachina/ >. Acesso em: 05 set. 2016.

FINEP. Estatuto da FINEP - Financiadora de Estudos e Projetos. Aprovado pelo Decreto n ${ }^{\circ} 1.808$, de 7 de fevereiro de 1996.

FOPROP. Ofício 009/FOPROP/2015. Destinatário: Professor Renato Janine Ribeiro. Ministro da Educação. Fórum de Pró-Reitores de Pesquisa e PósGraduação - FOPROP. Brasília, 14 de julho de 2015.

Ofício 011/FOPROP/2015. Destinatário: Professor Carlos Nobre. Presidente da CAPES. Fórum de Pró-Reitores de Pesquisa e Pós-Graduação FOPROP. Brasília, 28 de julho de 2015.

HIRSCHMAN, Albert O. A retórica da intransigência: perversidade, futilidade, ameaça. São Paulo: Companhia das Letras, 1992.

JUNEMANN, Carolina; BALL, Stephen. Pearson and palf: the mutating giant. This paper draws in part on a Leverhulme Trust research project: Philanthropy, Education Policy and Governance, June 2015.

MARX, Karl. A assim chamada acumulação primitiva. O Capital.São Paulo: Nova Cultural, 1985. p. 261-294.

O Capital. Livro 1. Vol 1. São Paulo: Abril Cultural, 1983.

MONTEIRO, Viviane. Anped reage a mudanças da Capes nos critérios de repasse de recursos para pós-graduação. Portal da SBPC. Jc Notícias. Disponível em:<http://www.jornaldaciencia.org.br/edicoes/?url=http://jcnoticias. jornaldaciencia.org.br/1-anped-reage-a-mudancas-da-capes-nos-criterios-derepasse-de-recursos-para-pos-graduacao/>. Acesso em: 05 set. 2016. 
MORUS, Thomas. A utopia. Disponível em:<http://www.dominiopublico.gov. $\mathrm{br} /$ download/texto/cv000070.pdf $>$. Originalmente publicado em: 1516. Acesso em: 15 ago. 2016.

NUNES, João Batista Carvalho. Análise da aplicação dos critérios de concessão do PROAP e PROEX. Disponível em:<http://www.anped.org.br/ sites/default/files/images/anexo_oficio_anped_033_2016_analise_tamanho_ corpo_discente_atualizado.pdf $>$. Acesso em:05 set.2016.

OLIVEIRA, João Ferreira de. A pós-graduação e a pesquisa no Brasil: processos de regulação e de reconfiguração da formação e da produção do trabalho acadêmico. Práxis Educativa, Ponta Grossa, v. 10, n. 2, p. 343-363, jul./dez. 2015.

PHILIPPI JR., Arlindo. Conferência de Abertura: Relevância Social e Econômica da Pesquisa e da Pós-Graduação. XXXI ENPROP - Encontro Nacional de Pró-Reitores de Pesquisa e Pós-Graduação, de 2015.Disponível em:<http:// capes.gov.br/sala-de-imprensa/noticias/7732-enprop-discute-relevancia-sociale-economica-da-pesquisa-e-da-pos-graduacao >. Acesso em: 01 set 2016.

SCHWAB, Klaus. The Fourth Industrial Revolution: what it means, how to respond. Disponível em:<https://www.weforum.org>. Acesso em: 05 sep. 2016.

SJR. Scimago Journal \& Country Rank. Disponível em <http://www. scimagojr.com/countryrank.php>. Acesso em: 31 ago 2016

VEIGA, João Marcos. Audiência na Câmara com presença da ANPEd demonstra equívocos de metodologia da CAPES no financiamento de programas de pósgraduação. Portal da ANPED, 31 ago 2016. Disponível em:<http://www. anped.org.br/news/audiencia-na-camara-com-presenca-da-anped-demonstraequivocos-de-metodologia-da-capes-no>. Acesso em: 05 set. 2016.

WOLDMAPPER. A world map based on scientific research papers produced. Disponível em:< http://www.worldmapper.org/>. Acesso em: 05 set. 2016.

MÁRIO LUIZ NEVES DE AZEVEDO é professor titular na Universidade Estadual de Maringá (UEM). Mestre em Educação pela Universidade Federal de São Carlos (UFSCar). Doutor em Educação pela Faculdade de Educação da Universidade de São Paulo (USP), com estágio de pesquisa, apoiado pela CAPES,

802 - RBPAE - v. 32, n. 3, p. 783 - 803 set./dez. 2016 
no Institut National de Recherche Pédagogique (INRP-França). Pós-doutorado na Universidade de Bristol (UoB-Inglaterra), no Centre for Globalisation, Education and Societies. Coordenador do Programa de Pós-graduação em Educação (PPE-UEM). Pesquisador da Rede Universitas/Br, participando do OBEDUC "Políticas da Expansão da Educação Superior no Brasil". Membro do Comitê Científico Nacional da ANPEd (2013-2015). Diretor Financeiro da ANPEd (2015-2017). Pesquisador do CNPq. E-mail: mlnazevedo@uem.br

JOÃO FERREIRA DE OLIVEIRA é professor associado na Universidade Federal de Goiás (UFG). Mestre em Educação pela UFG (1994). Doutor em Educação pela Faculdade de Educação da Universidade de São Paulo (USP). Pós-doutorado em Educação pela USP. Presidente da ANPAE - Associação Nacional de Políticas e Administração da Educação (Biênio 2015-2017)). Membro do Comitê de Assessoramento da Educação no CNPq - CA/Ed (2013-2016). Integra a Câmara de Assessoramento da Área de Ciências Humanas da FAPEG. Membro do Conselho Científico do Fórum da Gestão do Ensino Superior nos Países e Regiões de Língua Portuguesa (FORGES). Coordenador da Rede de Pesquisa Universitas/Br (2014-2016). Coordenador do DINTER PPGE/UFG-UEG (2015-2018). Vice-presidente da Anped (2010-2013). Coordenador de Programa de Pós-graduação em Educação da UFG (entre 2006 e 2009). Pesquisador do CNPq. E-mail: joao.jferreira@gmail.com

AFRÂNIO MENDES CATANI é professor titular na Faculdade de Educação da Universidade de São Paulo (USP). Mestre em Sociologia pela Universidade de São Paulo (USP). Doutor em Sociologia pela Universidade de São Paulo (USP). Livre-Docente no período 2006-2009. Também é professor no Programa de Pós-Graduação em Integração da América Latina (PROLAM-USP). Parecerista de agências como CNPq e Fapesp. Atua nas áreas de Educação, com ênfase em Sociologia da Educação e de cinema latinoamericano, destacando-se os seguintes temas em suas investigações: Pierre Bourdieu, políticas de educação superior (América Latina) e cinema na América Latina. Pesquisador da Rede Universitas/ Br, participando do OBEDUC "Políticas da Expansão da Educação Superior no Brasil". Pesquisador da Rede Universitas/Br, participando do OBEDUC "Políticas da Expansão da Educação Superior no Brasil". Pesquisador do CNPq. E-mail: amcatani@usp.br 